\title{
Role Stress in Adolescents of Employed and Unemployed Mothers
}

\author{
Ajit Kaur \\ Guru Nanak Dev University, India
}

\begin{abstract}
The present study was undertaken in 2011 to investigate role stress among adolescents of employed and unemployed mothers. The sample of the study consisted of 200 adolescent students from both the private and public secondary schools of Amritsar, India. Equal number of students were taken from year level 9 and 11. Bisht Battery of Stress Scales (BBSS) was used to measure role stress among students. The analysis of the data revealed that no significant difference exists in the level of role stress among boys and girls of both employed and unemployed mothers, that is, level of role stress is independent of gender and employment status of mothers. The study fills the gap in the literature by underscores the usefulness of role theory for explaining role stress among adolescents of both employed and unemployed mothers. Furthermore, adolescents' role relationships should be the focus of intervention and prevention to promote their healthy psychosocial development. Findings are discussed in the light of previous literature. Theoretical and empirical implications of findings and directions for future research are also discussed.
\end{abstract}

\section{Introduction}

Adolescent is the most important and critical period of individuals development. It refers to the period of development and adjustment during the traditional period between childhood and adulthood [3]. During this period, the establishment of childhood goes away, and a revolutionary process of chain starts. The term adolescence comes from the word 'adolescere', which means to grow, or to grow to maturity. Erikson [8], in his Psychosocial Development Theory defined adolescence age as 'role versus identity confusion'.

The students at adolescent age are more under stress because of one or the other reason as stress especially affects the secondary school students who are at the major threshold of life [12]. Stress is the most common psychological disorder in school aged children and adolescents worldwide. Stress is the bad feeling occurs due to trouble beyond our control. This include only the two ideas about stress that are almost universal, first is that stress is unpleasant, and the second one is that something that happened to us and for which we can do little about.

It is not uncommon for students, overwhelmed with stress to experience headaches, indigestion fever and blackouts before and during exams [21]. Other physical symptoms, including excessive sweating stomach, nausea, shortness of breath, palpitation and dry mouth, poor concentration, blanking out, confusion, and poor organization, are also warning signs of stress. Students suffering from stress think negatively, fear failure, experience feelings of inadequacy and compare themselves unfavorably to others. The objectives and hypotheses are detailed below:

- Objectives

i. To study the level of role stress among adolescents of employed and unemployed mothers.

ii. To study the level of role stress among boys and girls of employed mothers.

iii. To study the level of role stress among boys and girls of unemployed mothers.

- Hypotheses

i. No statistically significant difference exists in the level of role stress among adolescents of employed and unemployed mothers.

ii. No statistically significant difference exists in the level of role stress among boys and girls of employed mothers.

iii. No statistically significant difference exists in the level of role stress among boys and girls of unemployed mothers.

Stress has been defined as the "general adaptation syndrome [20]. In the biological sense stress is the interaction between damage and defence, just as in physics stress or pressure represents the interplay between a force and the resistance offered to it" 
[20]. According to Lazarus [13] stress is an interaction between person, and the environment, in which the demands tax or exceed the person's resources. Whereas Jones [11] explained that stress is a "source of negative conditions experienced by people of all ages from a variety of cultures".

\section{Stress and its Effects}

Stress is used to describe a situation in which individuals are faced with demand that exceed their immediate ability to cope [11]. It is anxiety and distress caused by any pressure or stress. It is caused by modern symptom associated within social pressure, which imposes a variety of duties and obligations on the individual. The links between stress, health and disease are complex and need to be examined carefully. Excessive stress over a long period of time has been linked with such ailments as headache stiffness, pains, tiredness, lack of energy, emotional outbreak, loss of appetite, anxiety, depression, dissatisfaction, boredom, semantic complaints psychological fatigue, feelings of futility, inadequacy, low self-esteem, alienation, anger, repression, loss of concentration. It leads to increasing dependence on smoking, alcohol, and other drug habits among adolescents. Stressful life events and emotional problems are powerful predictors of alcohol abuse among adolescents because they believe that alcohol can deceive severe anxiety [3].

According to American Psychological Association (APA), the following are different kinds of stress:

i. Acute stress - It is a common form of stress, a person having acute stress is generally emotionally distressed. $\mathrm{He}$ has a muscular problem that is headache, back pain, joint pain, etc.

ii. Episodic stress - An individual with episodic stress found disaster around every corner and pessimistically forecast catastrophe in every situation. The world becomes dangerous, where awful is always about to happen. The person with this stress reports persistent stress, headache, migraine, and hyper stress.

iii. Chronic stress is reported as a kind of stress in which a person unable to find a way out from a miserable situation. It kills through suicide, heart attack or perhaps even cancer.

In India main cause of chronic stress among adolescents is perhaps high expectations and parental pressure for academic achievement. Moreover, the fear of competition also causes stress as the number of higher educational institution is far less than the number of students. Therefore, parents pressurise their children to perform well than all others in their exams, and all this eventually gives birth to different kinds of stress, such as:

Examination stress has been characterized as "evaluative apprehension" or "evaluative stress" of formal examination, results in such high degree of anxiety in many students, that they are unable to perform at the usual level which they have shown in less stressful situation otherwise.

Competition is a striving on the part of two or more persons for the same object especially for the goal of being superior. Competition creates despair in the slow learners and stress in the bright one; to whom coming of second best represent grace.

iv. Success vs Failure - In most academic settings, the obvious solution to problems of how to get students of all levels of ability to realize more of their potentiality for learning is that of increasing academic pressure on them that urge them to do better. Sometimes such measures will work but more they will not. Usually, they only serve to aggravate the sense of failure that already troubles such students.

Stress can be managed with various test management techniques, which refer to the efforts to control and reduce the stress that occurs with situations that is considered difficult or unmanageable proper training, self-activity and exercise can reduce its impact. Riana [17] listed some of the behavioural, physiological and health effects, which have been suggested to be linked to the experience of stress. These effects are as follows:

i. Psychological or Subject effects - Anxiety, aggression, fatigue, frustration, low self-esteem, threat, and stress.

ii. Behavioural effects - Accident proneness, drug taking, emotional outbursts, excitability, impulsive behaviour, and restlessness.

iii. Cognitive effects - Problem in decision making and concentration, frequent forgetfulness, and mental block.

iv. Physiological effects - Increase in blood and glucose level, increase heart rate and sweating, and lump in the throat.

v. Health effects - Asthma, chest and back pains, coronary heart disease, nightmare, insomnia, psychosomatic disorder, ulcer, and weakness. 
vi. Organization health - Absenteeism, poor working environment, high accident rates, poor productivity.

However, excessive, and unremitting stress leads to maladaptive behaviour. When there is stress, which the student cannot cope with, the teacher must try to remove it from them for some time. However, preventing excessive stress is not enough, ultimately the student must learn to deal with many kinds of stress that will be inevitable in their life. It is only gradually that they will acquire the skill to deal with stress.

Thus, from above discussion, it is clear that if stress among dolphins is not given due consideration in its initial stages, it may result in the end of life, that is death. So, whether the mother is employed or unemployed, both having equal responsibility towards their children during adolescence. No doubt the difficulty level of both kinds of mothers is different, as employed mothers face more difficulty to handle their child due to dearth time they can spend with their child, and unemployed mothers finds it difficult because of lack of their exposure of outside world. So, this study helps all such mothers to know about the level of stress among their children during adolescent period and how to reduce that stress so that they can help their wards to show the better academic achievement.

From the time of birth an individual plays a variety of roles such as that of son/daughter, brother/sister/, friend/foe etc. each of these positions or roles occupied by an individual are connected by a set of norms or guidelines for appropriate behavior [6]. These guidelines or role prescriptions are devised by society. The individual's understanding of these roles (role perception) may be faulty or correct, determine the ways in which he/she behaves (role enactment) [6], [16]. Furthermore, every individual plays a variety of roles simultaneously in life: student, son, brother etc., where each of these roles require different types of behavior which often cause problems in relationships. The ensuing stress, that is, stress due to the multiple roles an individual plays in life called role stress [6], [7], [14].

Stress is associated with substantial effects on individuals' social, emotional, and academic development [3], [22]. Some of the negative effects of role stress include, poor social and coping skills, often leading to avoidance of social interactions, loneliness, low self-esteem, perception of rejection and difficulty in forming friendships [13]. Therefore, gaining insight into the role stress in adolescents of both employed and unemployed mothers adds to the existing body of knowledge. As tendency to enter the workforce has been increased among women, therefore, to know whether mother's employment affects adolescents' level of role stress is an issue of scientific enquiry [5].
With respect to employed and unemployed mothers' researchers are divided in their opinions. Some researchers are of the view that adolescents of employed mothers are more under stress as compared to their counterparts as they do not have enough time to spend with their children and to attend their problems [7], [10], [19], [23]. On the contrary, other researchers suggested that adolescents of employed mothers face less stressful situations as they are emotionally mature and can handle the situations much better than the adolescents of unemployed mothers, who encounter more such situations in comparison [1], [2], [9], [18]. Either way, adolescents of both employed and unemployed mothers are reported under stress. Moreover, mothers' employment status had a greater effect on female adolescents than on their counterparts and they tended to assure greater responsibility for household tasks [5]. Therefore, an understanding of employment status of mothers and gender differences in role stress among adolescents may help in developing plans to optimize the adolescents' productive activities for achieving goals of education.

\section{Methodology}

Analysis is deliberative, scientific, and intentional deliberation. The adoption of appropriate action is very necessary after the selection, classification, and delimitation of the issue. Research preparation and procedures are considered necessary to save it from being a heap of jumbled ideas collected from here and there. In general, the ultimate success of any research project depends on the methods employed. In every piece of research different method are used at different stages. The discussion about the method to be selected depends upon the nature of the problem to be selected and kind of data necessary for its solution. The aim of current study was to investigate the impact of role stress on academic achievement among adolescents of employed and unemployed mothers, whereas this paper focused on one aspect of that research that differences in the level of role stress in terms of gender and employment status of mothers. Cross-sectional quantitative survey (paper pencil based) was conducted in 2011 to investigate gender differences in role stress among adolescents of both employed and unemployed mothers. Purposive and incidental sampling techniques was used to select the sample for current study, where sample consisted 200 students studying in year level 9 and 11 from 10 secondary schools of Amritsar, a major city of Punjab state in India. Out of 200 adolescents, 100 adolescents were of employed mothers. Out of 100 adolescents of employed mothers, 50 were boys and 50 were girls. Out of 50 boys, 25 were from year level 9 and other 25 were from year level 11 . Out of 50 girls, 25 were from year level 9 and other 25 were from year level 11. 
Similarly, among 200 adolescents, 100 adolescents were of unemployed mothers. Out of 100 adolescents of unemployed mothers, 50 were boys and 50 were girls. Out of 50 boys, 25 were from year level 9 and other 25 were from year level 11 . Out of 50 girls, 25 were from year level 9 and other 25 were from year level 11.

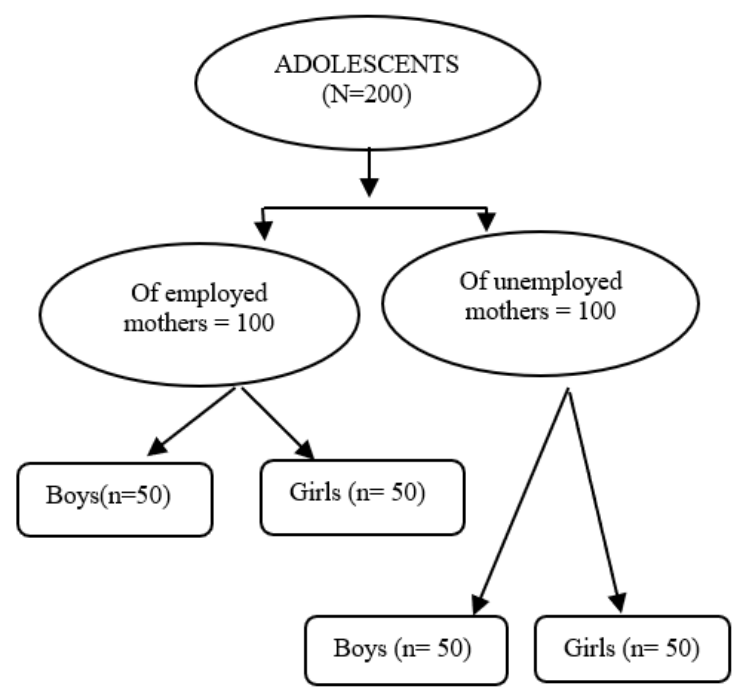

Figure 1. Graphical representation of sample

\section{Measures}

To measure the role stress in adolescents [14], the Scale of Role Stress (SRS) from Bisht Battery of Stress Scales developed by Abha Bisht [4] was used. Reliability of the scale of the battery was calculated in three ways dependability: short term test-retest correlations (.78); stability: retest after longer interval (.76); internal consistency: split half correlations and score on each of the component $(\alpha=.84)$. Internal consistency of the scale of role stress was .84 (see Table 1). The scale has both content validity and item validity. For the measurement of thirteen types of stressor, this battery contains thirteen scales in it, as listed below:

1. Scale of existential stress

2. Scale of achievement stress

3. Scale of academic stress

4. Scale of self-concept stress
5. Scale of self-actualization stress

6. Scale of physical stress

7. Scale of social stress

8. Scale of role stress

9. Scale of institutional stress

10. Scale of family stress

11. Scale of vocational stress

12. Scale of financial stress

\section{Scale of superstition stress}

The inventory items are distributed over the four components of the different types of stressors (see Table 2). First is frustration in which items are based on delays, lack of resources, losses, and failure (Bisht, 1987). Second, Items related to conflict shows three types of conflict approach: avoidant approach, double approach, and double avoidant approach [4]. Third category is related to pressure in which items are on competitive achievement, sustained concentration of efforts and rapid change. Items related to anxiety are divided into categories worry and emotionality. The worry items of anxiety are on conscious concern about consequences, negative expectations, and negative self-evaluation. The emotionality items are uneasiness and nervousness. As for the present only role stress scale was used. The scale consists of 48 items on 5point Liker scale in terms of both frequency; always, often, sometimes, rarely, never, and quantity; too much, much, average, less, not at all (see Table 3). The total is separate for frequency and quantity. The grand total is the sum of frequency score and quantity score. Thus, each scale yield

a) Frequency of stress score

b) Quantity of stress score

c) Total stress score

Table 1. Showing dependability, stability, and internal consistency, coefficients of role stress scale

\begin{tabular}{|c|c|c|c|}
\hline Scales & $\begin{array}{c}\text { Depend- } \\
\text { ability }\end{array}$ & Stability & $\begin{array}{c}\text { Internal } \\
\text { Consistency }\end{array}$ \\
\hline SRS & .78 & .76 & .84 \\
\hline
\end{tabular}


Table 2. Showing internal consistency coefficients correlation between total and component scores on role stress scale

\begin{tabular}{|c|c|c|c|c|}
\hline Scale & Frustration & Conflict & Pressure & Anxiety \\
\hline SRS & .42 & .51 & .29 & .23 \\
\hline
\end{tabular}

Table 3. Showing distribution of scores on role stress scale

\begin{tabular}{|c|c|c|c|c|c|}
\hline Frequency & Always & Often & Sometimes & Rarely & Never \\
& & & & & \\
\hline Quantity & Too much & Much & Average & Less & Not at all \\
\hline Positive & 4 & 3 & 2 & 1 & 0 \\
\hline Negative & 0 & 1 & 2 & 3 & 4 \\
\hline
\end{tabular}

As for the present study, role stress was discussed. Therefore, items for scale of role stress are distributed over the four types of role stress:
a) Sex-role stress
b) Status role stress
c) Variety for role stress, and
d) Role confusion stress

\section{Data analysis}

Analysis of data means studying the tabulated value to determine inherent facts or meanings. It involves breaking down of complex factors into simple parts and putting the parts into the arrangement for the purpose of interpretation. To achieve the objectives and to test the null hypothesis of the current study mean, SD, and t-test analysis was conducted. ttest analysis was computed to determine the difference in the level of role stress among adolescent boys and girls of employed and unemployed mothers. Figures and Tables were drawn to make the results transparent.

\section{Result and Discussion}

Hypothesis 1 - No statistically significant difference exists in the level of role stress among adolescents of employed and unemployed mothers. For the verification of above-mentioned hypothesis, raw scores of adolescents of employed and unemployed mothers were calculated, based on their raw scores, the categorized were detailed below.

It is clear from the Table 4 that majority of adolescents of employed and unemployed mothers lie in the category of average stress on variable role stress. To find out whether this difference is statistically significant or not, various statistical techniques, that is, mean, standard deviation (SD), standard error (S.E) of difference between means and $\mathrm{t}$-value were calculated and presented in Table 5.

Table 4. Showing category-wise distribution of adolescents of employed and unemployed mothers on the variable role stress

\begin{tabular}{|c|c|c|c|}
\hline Categories & $\begin{array}{c}\text { Adolescents } \\
\text { of employed } \\
\text { mother }\end{array}$ & $\begin{array}{c}\text { Adolescents } \\
\text { of } \\
\text { unemployed } \\
\text { mothers }\end{array}$ & Total \\
\hline High stress & 35 & 23 & 58 \\
\hline $\begin{array}{c}\text { Average } \\
\text { stress }\end{array}$ & 47 & 45 & 92 \\
\hline Low stress & 18 & 32 & 50 \\
\hline Total & 100 & 100 & 200 \\
\hline
\end{tabular}

Table 5. Showing the level of role stress among adolescents of employed and unemployed mothers

\begin{tabular}{|c|c|c|c|c|c|}
\hline Group & $\mathrm{N}$ & Mean & SD & S. E & t-value \\
\hline $\begin{array}{c}\text { Adolescents } \\
\text { of employed } \\
\text { mothers }\end{array}$ & 100 & 106 & 23.3 & 3.20 & \\
\hline $\begin{array}{c}\text { Adolescents } \\
\text { of } \\
\text { unemployed } \\
\text { mothers }\end{array}$ & 100 & 100.5 & 21.9 & & \\
\hline
\end{tabular}

The Table 5 mean of role stress among adolescents of employed mothers and unemployed mothers is 106 and 100.5, respectively. The standard deviation of employed and unemployed mothers is 23.3 and 21.9, respectively. The mean scores shows that adolescents of employed mothers are better than adolescents of unemployed mothers with respect to their role stress. To find whether this difference is significant or not $\mathrm{t}$ test was applied, and calculated t-value. This test was found to be statistically insignificant $t(200)=1.72, p$ $=0.001$. Thus, the result indicated that adolescents of 
both employed and unemployed mothers do not differ with respect to their level of role stress. Which contradicts the finding of other research studies who were of the view that significant difference exists in stress level of working and non-working mothers [15], [18].

Hypothesis 2 - No statistically significant difference exists in the level of role stress among boys and girls of employed mothers. For the verification of above-mentioned hypothesis, raw scores of boys and girls of the employed mothers were calculated, based on their raw scores they were categorized as follows:

Table 6. Showing category-wise distribution of boys and girls of employed mothers on the variable role stress

\begin{tabular}{|c|c|c|c|}
\hline Categories & $\begin{array}{c}\text { Boys of } \\
\text { employed } \\
\text { mother }\end{array}$ & $\begin{array}{c}\text { Girls of } \\
\text { employed } \\
\text { mothers }\end{array}$ & Total \\
\hline High stress & 13 & 22 & 35 \\
\hline $\begin{array}{c}\text { Average } \\
\text { stress }\end{array}$ & 27 & 20 & 47 \\
\hline Low stress & 10 & 08 & 18 \\
\hline Total & 50 & 50 & 100 \\
\hline
\end{tabular}

It is clear from the Table 6 that majority of boys and girls of employed mothers lie in the category of average stress on variable role stress. To find out whether this difference is statistically significant or not, various statistical techniques, that is, mean, standard deviation (SD), standard error (S.E) of difference between means and t-value were calculated and presented in Table 7.

Table 7. Showing the level of role stress among boys and girls of employed mothers

\begin{tabular}{|c|c|c|c|c|c|}
\hline Group & $\mathrm{N}$ & Mean & SD & S. E & t-value \\
\hline $\begin{array}{c}\text { Boys of } \\
\text { employed } \\
\text { mothers }\end{array}$ & 50 & 104.4 & 24.9 & 4.7 & 0.71 \\
\hline $\begin{array}{c}\text { Girls of } \\
\text { employed } \\
\text { mothers }\end{array}$ & 50 & 107.7 & 21.7 & & \\
\hline
\end{tabular}

The Table 7 mean of role stress among boys and girls of employed mothers are 104.4 and 107.7, respectively. The standard deviation of boys and girls of employed mothers are 24.9 and 21.7 , respectively. While looking at mean scores it is found that boys of employed mothers are better than girls of employed mothers with respect to their role stress. To find whether this difference is significant or not t-test was applied, and calculated t-value. This test was found to be statistically insignificant $t(100)=0.71, p=0.001$. Thus, the result indicated that both boys and girls of employed mothers do not differ with respect to their level of role stress. Which supports the finding of other research studies who were of the view that maternal involvement is important for the mental health of both boys and girls [13].

Hypothesis 3 - No statistically significant difference exists in the level of role stress among boys and girls of unemployed mothers. For the verification of above-mentioned hypothesis, raw scores of boys and girls of the unemployed mothers were calculated, based on their raw scores they were categorized as follows:

Table 8. Showing category-wise distribution of boys and girls of unemployed mothers on the variable role stress

\begin{tabular}{|c|c|c|c|}
\hline Categories & $\begin{array}{c}\text { Boys of } \\
\text { employed } \\
\text { mother }\end{array}$ & $\begin{array}{c}\text { Girls of } \\
\text { employed } \\
\text { mothers }\end{array}$ & Total \\
\hline High stress & 15 & 08 & 23 \\
\hline $\begin{array}{c}\text { Average } \\
\text { stress }\end{array}$ & 18 & 27 & 45 \\
\hline Low stress & 17 & 15 & 32 \\
\hline & & 50 & 100 \\
\hline Total & 50 & 50 & \\
\hline
\end{tabular}

Table 9. Showing the level of role stress among boys and girls of unemployed mothers

\begin{tabular}{|c|c|c|c|c|c|}
\hline Group & $\mathrm{N}$ & Mean & SD & S. E & t-value \\
\hline $\begin{array}{c}\text { Boys of } \\
\text { unemployed }\end{array}$ & 50 & 100.1 & 24.3 & 4.4 & \\
\cline { 1 - 3 } $\begin{array}{c}\text { Girls of } \\
\text { unemployed } \\
\text { mothers }\end{array}$ & 50 & 100.9 & 19.7 & & 0.18 \\
\hline
\end{tabular}

It is clear from the Table 8. that majority of boys and girls of unemployed mothers lie in the category of average stress on variable role stress. To find out whether this difference is statistically significant or not, various statistical techniques, that is, mean, standard deviation (SD), standard error (S.E) of difference between means and t-value were calculated and presented in Table 6.

The Table 9 mean of role stress among boys and girls of unemployed mothers are 100.1 and 100.9, respectively. The standard deviation of boys and girls of employed mothers are 24.3 and 19.7, respectively. While looking at mean scores it is found that boys of unemployed mothers having near about same level of role stress as that of girls of unemployed mothers with respect to their role stress. To find whether this difference is significant or not t-test was applied, and calculated t-value. This test was found to be statistically insignificant $t(100)=0.18, p=0.001$. Thus, the result indicated that both boys and girls of unemployed mothers do not differ with respect to their level of role stress. Which conforms the finding of Sunita [24] that no significant differences were found in frustration scores of boys and girls of non-working mothers. 


\section{Limitations of the Study}

The study was limited to adolescent boys and girls. Future studies can be conducted to examine gender differences in role stress among other age groups. Also, to the adolescents studying in year level 9 and 11. Future studies can include adolescents from other year levels such as year level 8,10 and 12 .

The study was limited to secondary schools of Amritsar city only. However, future studies must be conducted among adolescents of other cities and states of India and other countries.

\section{Conclusion}

Today's world is highly competitive or academic achievement considered to be passport to success. The desire to attain higher academic achievement put a lot of pressure on students, but if an individual takes himself away from unnecessary stress or pressure. It leads to good mental health, which helps in higher academic achievement.

Parents especially mothers should therefore try to maintain how they approach toward their children to improve their academic achievement. The research studies also shows that the academic achievement and stress are significantly correlated should be taken by both teachers and parents, enable the students to handle the stressful situation and understanding of status on mothers that is employed and unemployed and role or vocational stress and the effect on again with achievement may help in developing plan to optimize a student's productive activities for achieving goals of education in present study the researcher has chosen that sense of secondary schools because they are under great stress and strain, the young generation is facing the greatest advancement in education, increase crisis and rapidly changing culture inappropriate emergence of stress may result in poor academic achievement. The purpose of this study is to thoroughly examine the effect of stress on academic achievement of secondary school schools have employed, an inquiry model, so that it may help in educationist teachers, parents and guidance workers in solving stress related problems, among adolescents, that need to improve their academic achievement this prompts the researcher to work on the above-mentioned problem.

The study investigated the role stress in adolescents and highlighted stress levels of adolescents in terms of gender differences as well as employment status of mothers. Study results showed that adolescents of both employed and unemployed mothers were experiencing the same level of role stress. There exists no significant difference in the level of role stress among adolescents of employed and unemployed mother, that is, level of stress is independent of the employment status of mothers. Results of the study also revealed that both boys and girls of employed mothers as well as unemployed mothers reported the same level of role stress. There exist no significant differences in the level of role stress among boys and girls of employed mothers, that is level of stress is independent of gender. Similarly, there exist no significant differences in the level of role stress among boys and girls of unemployed mothers. Therefore, this study has important implications for all stakeholders. Firstly, families and schools should create such an environment that may decrease the level of role stress among adolescents to develop a positive attitude and self-confidence in them. Role stress of adolescents did not differ significantly with respect to employment status of mothers. Both employed and unemployed mothers need to be more careful regarding their time management and need to be available to their child as and when they need care and guidance. Moreover, current study highlighted the importance of role stress in adolescents, which the educational policy makers should consider while framing plans and policies for adolescent students. Thus, present study brings awareness about role stress in adolescents among their parents and other stakeholders and can guide them to take necessary interventions.

\section{Future Research}

Future research can apply qualitative research methods to gain in-depth understanding of adolescents' experiences of role stress, which may highlight gender differences and/or differences due to employment status of mothers.

And the interrelationship of role stress with other potential stressors of adolescents such as vocational stress, existential stress, social stress, and other related stressors.

\section{References}

[1] Aghdam, F. B., Ahmadzadeh, S., Hassanalizadeh, Z., Ebrahimi, F., Sabzmakan, L., and Javadivala, Z. (2015). The effect of maternal employment on the elementary and junior high school students' mental health in Maku. Global journal of health science, $7(2), 379$.

[2] Anand, D. (2001). Sex differences in the stressful situation among high school students. Indian psychological abstracts and reviews, 6(1), 23-35.

[3] Andersen, S. L., and Teicher, M. H. (2008). Stress, sensitive periods and maturational events in adolescent depression. Trends in neurosciences, 31(4), 183-191.

[4] Bisht, A.R. (1987) Manual of Bisht Battery of Stress Scales. Agra, national psychological corporation.

[5] Burke, R. J., and Weir, T. (1978). Maternal employment status, social support and adolescents' well-being. Psychological Reports, 42(3), 1159-1170. 
[6] De Bryn Eddy, H. (2005). Role Strain, engagement, and academic achievement in early adolescence. Educational studies, 31(1), 15-27.

[7] Dunifon, R., Kalil, A., Crosby, D. A., and Su, J. H. (2013). Mothers' night work and children's behavior problems. Developmental Psychology, 49(10), 1874.

[8] Erikson, E. (1968). Identity: Youth and crisis: New York: Norton.

[9] Giraudo (1990). The relationship between family environment and school environment among 5th, 6th, and 7th grade students. Psychology reports, 31(3), 187-192.

[10] Hoffman, L. W. (1980). The effects of maternal employment on the academic attitudes and performance of school aged children. School psychology review, 9, 319 336.

[11] Jones, T. L. (2001). Definition of stress. Eating disorders in women and children: Prevention, stress management, and treatment, 89-100.

[12] Kaur, A. (2015). Impact of Role Stress and Vocational Stress on Academic Achievement among Adolescent Students. International Journal of Social Science and Interdisciplinary Research., 4(11), 81-85.

[13] Lazarus, R. S. (1990). Theory-based stress measurement. Psychological inquiry, 1(1), 3-13.

[14] Liu, R., and Kaplan, H. (2004). Role Stress and Aggression Among Young Adults: The Moderating Influences of Gender and Adolescent Aggression. Social Psychology Quarterly., 67(1), 88-102.

[15] Muni, A.K. and Panigrahi, B. (1998). Effect of maternal employment on school going children's adjustment problems. Psychology Abstracts and Reviews, $5(1), 1-5$

[16] Pearlin, L. I. (1983). Role strains and personal stress. Psychosocial stress: Trends in theory and research, 3-32.

[17] Raina, M.K. (1983). Biochemical consequences of examination stress. Indian Educational Review, 18(2), 1739.

[18] Sarita (2006). psychosocial problems of adolescent children of working and non-working mothers. Recent Research in Education and Psychology, 2(3), 12-18.

[19] Seenivasan, P., and Kumar, C. P. (2014). A comparison of mental health of urban Indian adolescents among working and non-working mothers. Annals of community health, 2(2), 39-43.

[20] Selye, H. (1950). Stress and the general adaptation syndrome. British Medical Journal, 1383.

[21] Sharma. (1995). Adolescents school adjustment. Sixth Survey of Educational Research, 26(2), 187-192.
[22] Sherrifrye (1998). Dealing with stress and studying its effect among preadolescents. New York, MC-Graw-Hills series publications.

[23] Singh, A., Kumar, H., and Kumari, S. (2020). Mental health of adolescents of working and non-working mothers. The International Journal of Indian Psychology, 8(3), 961966.

[24] Sunita (2005). A comparative study of frustration among the children of working and non-working mothers. Unpublished M.Ed. Dissertation, GNDU, Amritsar. 